\title{
Assessing Health Effects and Soundscape Analysis as New Mitigation Actions Concerning the Aircraft Noise Impact in Small- and Middle-Size Urban Areas in Greece
}

\author{
Georgia Gerolymatou ${ }^{1, *}$, Nicolas Rémy ${ }^{2,3}$, Konstantinos Vogiatzis ${ }^{1}$ and Vassiliki Zafiropoulou ${ }^{1}$ \\ 1 LTEA, School of the Civil Engineering, University of Thessaly, 38221 Volos, Greece; kvogiatz@uth.gr (K.V.); \\ ltea@uth.gr (V.Z.) \\ 2 Department of Architecture, Polytechnic School, University of Thessaly, 38221 Volos, Greece; nremy@uth.gr \\ 3 School of Architecture University Grenoble Alpes, Research Unit AAU-CRESSON, F-38036 Grenoble, France \\ * Correspondence: ggerolymatou@uth.gr; Tel.: +30-24210-74170
}

Received: 23 October 2018; Accepted: 24 December 2018; Published: 4 January 2019

\begin{abstract}
In 2013 and 2014, two main International Airports in Greece were evaluated through the European directive on noise environment 2002/49/EC: "Nikos Kazantzakis" International Airport of Heraklion Crete and "Ioannis-Kapodistrias" International Airport in Corfu, both located in highly touristic areas of Greece. Acoustic measurement's campaign, environmental noise mapping simulations and population exposure to noise were implemented in order to produce a complete Strategic Noise Map. Correlated to this acoustic approach, a comprehensive interview campaign and a detailed soundscape analysis were also conducted in both airports' adjacent areas (Alikarnassos district in Heraklion and the peninsula of Canoni in Corfu City) in order to understand the impact of aircraft movements on both local residents and tourists, and analyze the perception of the soundscapes. A similar evaluation was also executed in order to assess possible health effects by using the WHO's DALY's (Disability Adjusted Life Year) metrics for environmental noise in relation to the exposure of the population. This paper presents the main results of these representative case studies, attempting a combined assessment of both health effects and soundscape characteristics to be used as evaluation tools towards the management and the rehabilitation acoustic environment characterized mainly by aircraft noise in touristic areas.
\end{abstract}

Keywords: health effect; aircraft noise; environmental noise; European directive 2002/49; DALY metric; sound maps; sound perception; quiet zone; neighborhood; sound identity

\section{Introduction}

Noise pollution is a growing concern in Europe. More specifically, noise from transport [1] and industrial sources is of particular importance, addressed by Directive 2002/49/EC relating to the assessment and management of environmental noise, otherwise known as the Environmental Noise Directive [2]. Regarding environmental noise annoyance, especially from airport operation, it is widely accepted as an end-point of environmental noise that can be taken as a basis for evaluating the impact of noise on the exposed population. In recent years, the use of aircraft as an efficient transport system has greatly increased and many of the large airports and their incidence areas have incurred considerable operational difficulties, very often reaching situations of saturation. Furthermore, air traffic is projected to grow in the long term, driven by global GDP growth [3]. As a consequence, millions of people around the world already exposed to aircraft noise are likely to be subject to an increased aviation noise exposure, particularly near airport infrastructures. In fact, noise occurring during the landing and 
takeoff cycles are some of the most undesired environmental issues related to airport operations, and new mitigation measurements are necessary to protect residential areas [4]. Even though comparative analysis of methods to estimate urban noise exposure of inhabitants has been realized [5], a systematic approach to assess the effectiveness of airport noise mitigation strategies has been conducted [6], noise pollution continues to be a major health problem in Europe, with health effects recognized. People perturbed by airport noise may experience a variety of negative responses, such as anger, disappointment, dissatisfaction, withdrawal, helplessness, depression, anxiety, distraction, agitation, or exhaustion (see $[7,8]$ ). Many studies suggest that aircraft noise exposure may increase mortality from cardiovascular diseases [9].

As a result, airport operations, for example taxiing in landing and takeoff procedures, constitute a significant inconvenience factor [10] and [11], apart from a few cases, where they may be a special attraction for tourists. In this paper, two case studies are being presented and compared in order to show how health effects and soundscapes assessments can be combined in order to present new solutions for mitigating environmental noise pollution. Indeed, within the framework of the European Directive 2002/49/EC, the city of Heraklion (Greece) [11] and the city of Corfu (Greece) [12] completed their Strategic Noise Map (SNM) and the relevant Noise Action Plan (NAP). This paper presents the main results of these two representative case studies in an attempt to combine the assessments of both health effects and soundscape characteristics, in order to be used as an evaluation tool in regard to the management and the rehabilitation of the environment where it is mainly characterized by the aircraft noise in such areas.

The originality of this work lies in the multiplication of methodological approaches on the same object of work: namely, the noise emissions related to the activities of an international airport on a given territory. The methodology used for the production of the strategic noise maps and the action plans correlated is complemented by the assessment of the number of years lost thanks to the use of the DALY metric. Finally, these two analyses are supplemented and questioned by the systematic description of the perception of residents living close to the infrastructure in order to understand, through the discomfort expressed, where aircraft noise takes place. The objective is to propose new noise mitigation solutions that take into account all the sound sources of the environment, while at the same time take into consideration the geographical, urban, and cultural specificities of the sites.

\section{General Presentation of the International Airports}

\subsection{The International Airport of Heraklion}

In the prefecture of Heraklion, in Crete, the international airport "Nikos Kazantzakis" operates at a distance of $4.8 \mathrm{~km}$ from the city of Heraklion and is in direct contact with the urban agglomeration of Heraklion and the area of Alikarnassos. It is the biggest airport in Crete that occupies an area of 2781 acres and it has a corridor length of $2680 \mathrm{~m}$. The reference points of the airport are: Geographic latitude: $35^{\circ} 20^{\prime} 09^{\prime \prime}$, Geographic longitude: $25^{\circ} 10^{\prime} 25^{\prime \prime}$, and Altitude: $39 \mathrm{~m}$.

Within the frame of the Strategic Noise Mapping (SNM) program of the Greek Ministry of the Environment, a comparative Study on Aircraft Noise-according to European Directive 2002/49 [2] — was completed in 2013. As regards the number of aircraft movements, flights are based on an average annual $24 \mathrm{~h}$ basis, introducing the annual number of 2012's movements, according to the methodology ECAC29 \& AzB99. Figure 1 shows the aircraft movements for the year 2012 [11]. This Figure depicts the various AzB aircraft categories (P1, P 2.1, S 5.1, S 5.2, S 5.3) for the total aircraft movements for each runway (RW 09, RW 27). 


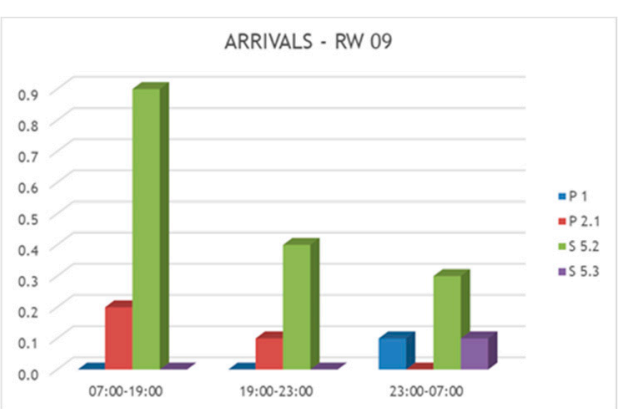

(a)

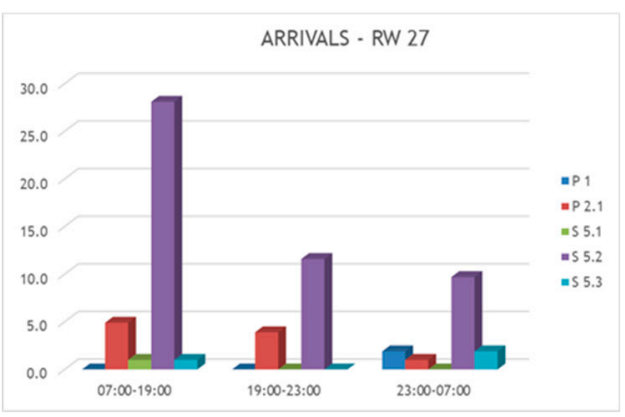

(c)

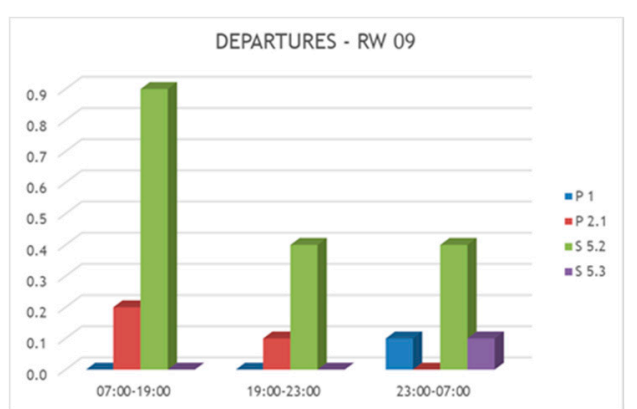

(b)

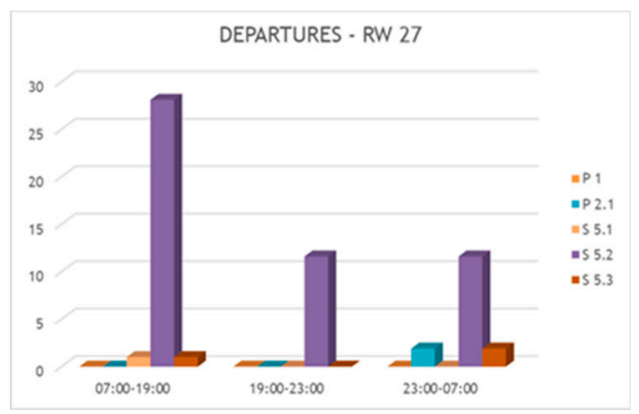

(d)

Figure 1. Annual average daily aircraft movements (TOffs \& landings) - 2012. Arrivals at RW 09(a), departures at RW 09(b), arrivals at RW 27(c), departures at RW 27(d).

Taking into account the needs of the Study on Aircraft Noise within the immediate and greater area of the International Airport "Nikos Kazantzakis", a three-dimensional model of the greater area was formed with the use of a Geographical Information System with the minimum geographical unity at the level of blocks of residences. Geographic limits of Heraklion agglomeration, location of the International Airport, and limits of Alikarnassos area are presented in Figure 2.

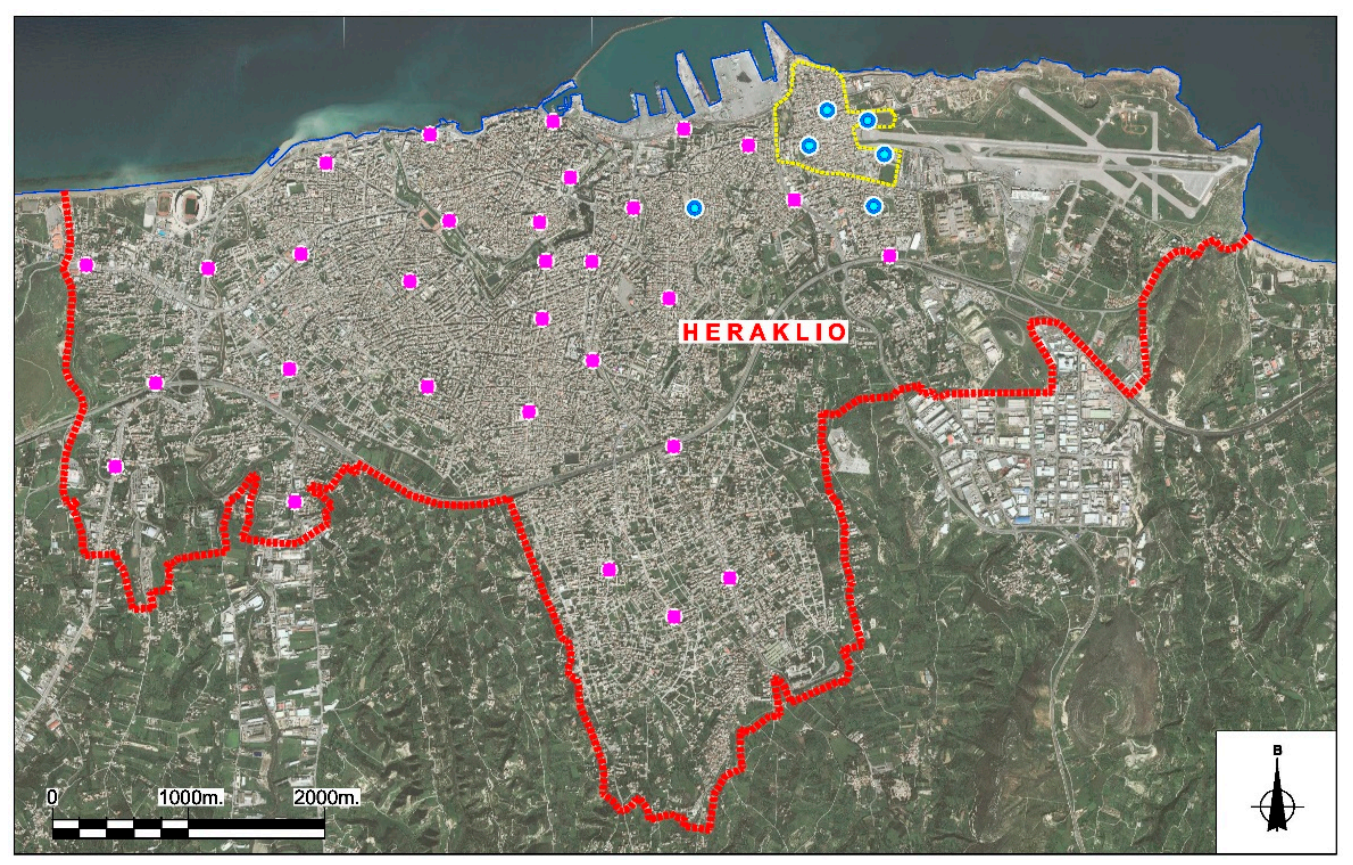

Figure 2. Geographical limits of the study subarea-Agglomeration of Heraklion (red dotted line)-Study area of Alikarnassos (yellow dotted line)-Positions of measurements for road traffic noise (magenta)—Positions of measurements for aircraft noise (blue). 
In 2013, according to the legislation and European Directive 2002/49, a full Strategic Noise Map (SNM) and Noise Action Plan (NAP) were completed. Given the efficiency of such an action plan $[12,13]$, we developed during several environmental studies a specific methodology in order to cross-analyze the acoustic data with the perception of the soundscapes $[14,15]$ and draw an global action plan for noise exposure and soundscape management. It has been applied to the subarea of Alikarnassos and the main results are presented in the following paragraphs.

\subsection{The International Airport of Corfu}

The International Airport "Ioannis Kapodistrias" is located at the southeast area of Corfu city. This area constitutes a major touristic zone with Kanoni and Pontikonisi welcoming every summer season a large number of tourists. The reference points of the airport are: Geographic latitude: $39^{\circ} 36^{\prime} 07^{\prime \prime}$, Geographic longitude: $19^{\circ} 54^{\prime} 44^{\prime \prime}$, and Altitude: $39 \mathrm{~m}$.

In 2013, according to the legislation and European Directive 2002/49, a full SNM and Noise Action Plan (NAP) were completed. Within the SNM calculations, the above subarea adjacent to the international airport was analyzed. The relevant subarea is located in the southern area of Corfu city, within a short distance from the historical center. The west side faces the airport and the closest residences are located less than $500 \mathrm{~m}$ from the runways, as is presented in Figure 3.

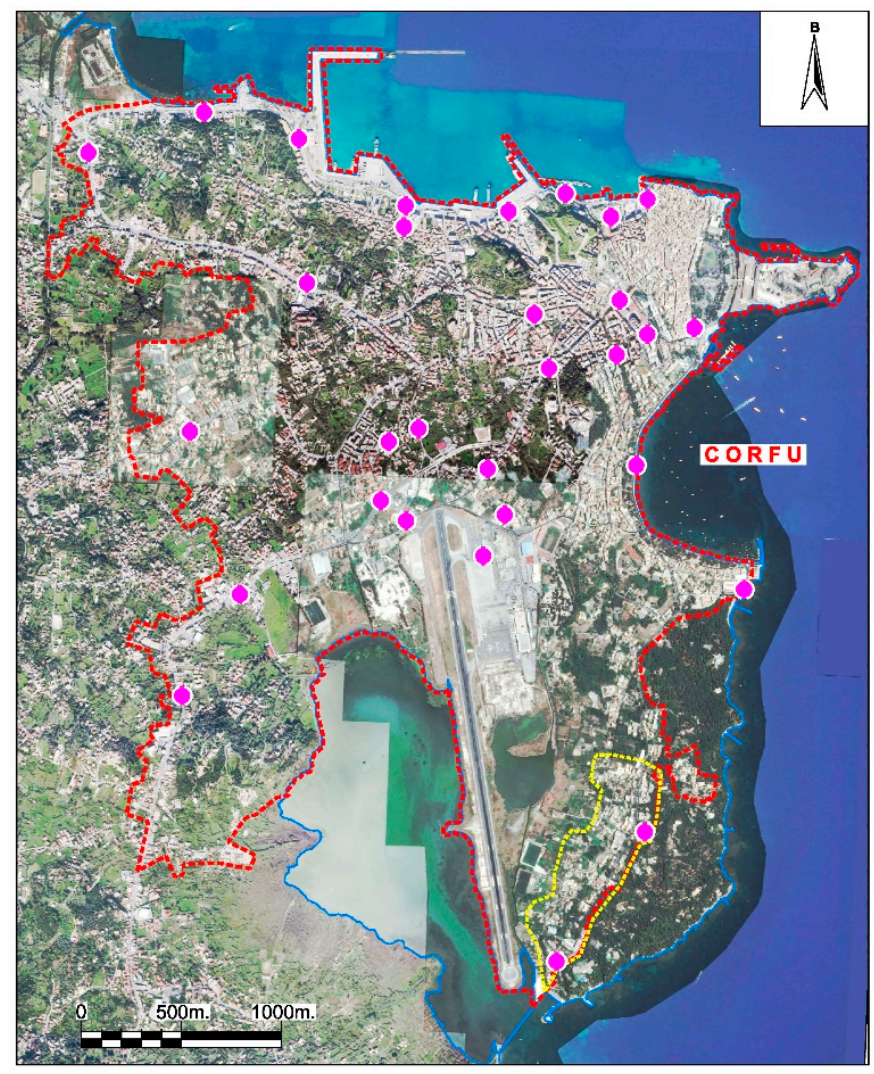

Figure 3. Geographical limits of the study subarea-Agglomeration of Corfu (red dotted line)—Study area of Kanoni (yellow dotted line)-Positions of measurements for road traffic and aircraft noise (magenta).

\section{Cross-Analysis of Three Methodological Protocols}

Acoustic measurements in situ, noise simulations, urban analysis, interviews with residents, DALY's metrics calculations have been cross-analyzed in three different protocols in order to pull out new ideas to manage noise from aircraft in middle-size urban areas. 


\subsection{Strategic Noise Maps Methodology}

According to European Directive 2002/49, all member States shall ensure that, no later than 30 June 2007, strategic noise maps showing the situation on the preceding calendar year will have been made and, where relevant, approved by the competent authorities, for all agglomerations with more than 250,000 inhabitants and for all major roads which have more than six million vehicle passages a year, major railways which have more than 60,000 train passages per year, and major airports within their territories [2]. In order to evaluate the sound impact and the relevant noise nuisance, we have developed a multidisciplinary methodology that simultaneously takes into account the real-time acoustic measurements and the SNM software prediction results that we cross with the results of interviews conducted in situ with inhabitants on the theme of acoustic comfort and sound identities [13].

Strategic noise maps were produced for the whole city using "CadnaA" acoustic prediction software including both airport and road traffic noise sources. Regarding road traffic environmental noise, the French national method of calculation "NMPB-Routes-96 (SETRA-Certu-LCPC-CSTB)" is applied, as stated in "'Arrêté du 5 mai 1995 relatif au bruit des infrastructures routières, Journal officiel du 10 mai 1995, Article 6" and the French standard "PS 31-133". In the relevant guidelines, this method is referred to as the "XPS 31-133" method. This method describes a detailed procedure for calculating the sound caused by road traffic near a road, taking into account the impact of weather conditions affecting propagation. As far as the environmental aircraft noise, the method of calculation is ECAC. CEAC Doc. 29, "Report on Standard Method of Computing Noise Contours around Civil airports", 1997 [16]. From the various methods of simulation of the volatile routes, the segmentation technique is used, as mentioned in part 7.5 of the ECAC. CEAC Doc. 29.

A detailed 3D model for both areas, including the International Airports based on the latest and most accurate cadaster and town planning data, was implemented. In order to calibrate the model and achieve the best correlation between measured and calculated noise values, a full $24 \mathrm{~h}$ noise measurement monitoring program was executed in the same period with the questionnaires survey. Then, $24 \mathrm{~h}$ acoustic measurements were executed by using class 1 statistical noise analyzers, on special-designed masts securing the European directive guidelines. The measurement results were compared with the theoretical results from the CadnaA [11,12], as presented in the following Figure 4. 

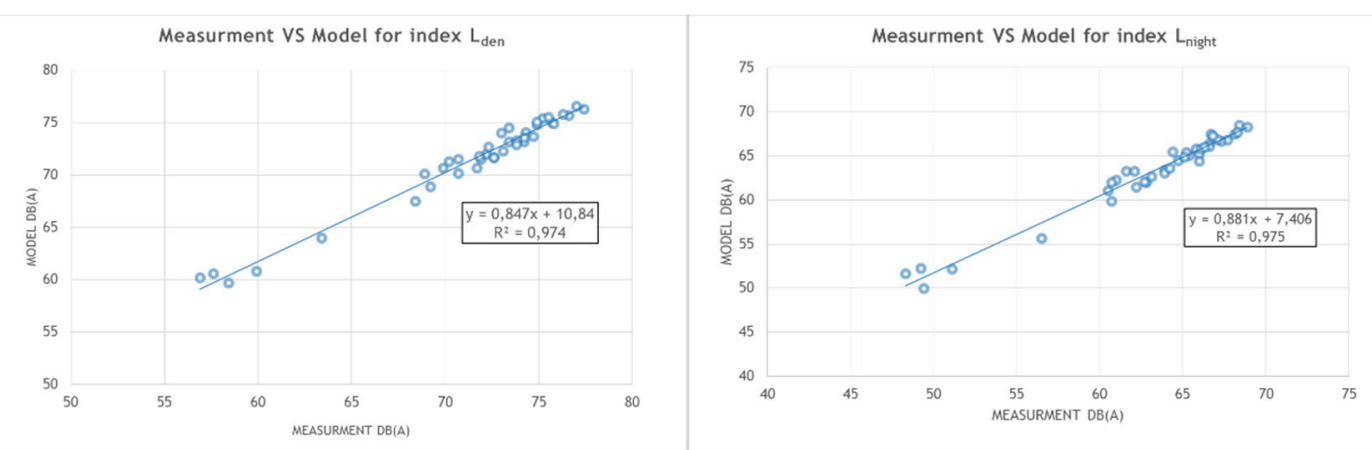

(a)
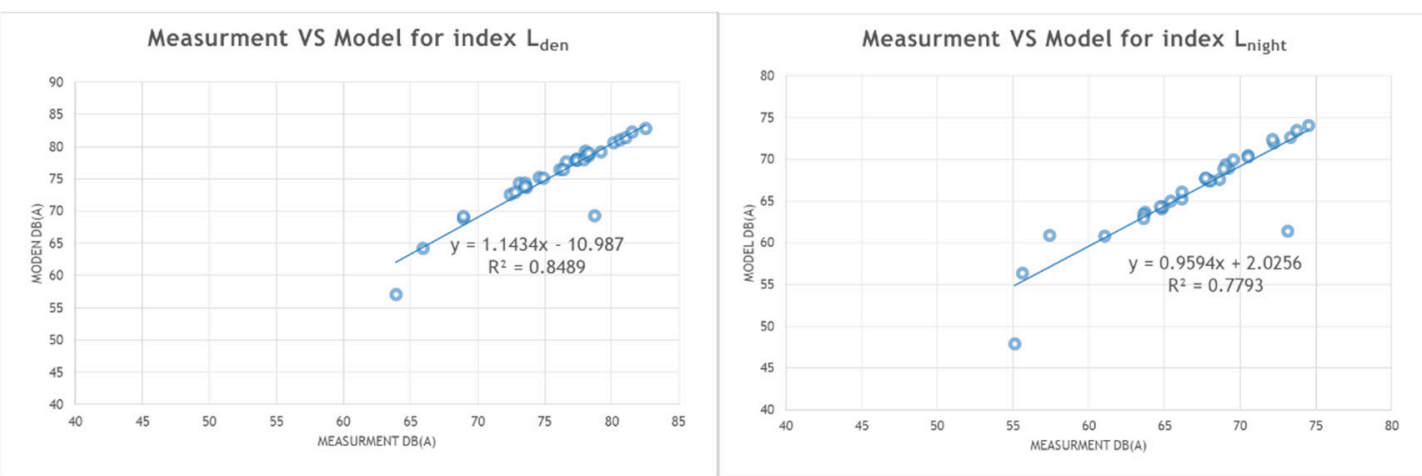

(b)

Figure 4. Comparison between the theoretical results from the CadnaA and the measurement results in the city of Heraklion (a) and in the city of Corfu (b).

\subsection{Noise Health Assessment Methodology}

According to the World Health Organization and "Burden of disease from environmental noise, Quantification of healthy life years lost in Europe" [17], the burden of disease is expressed in DALYs. In other words, Disability Adjusted Life Year or DALY combines in general population the years that people live with disabilities (YLD) and the years lost due to premature mortality (YLL):

$$
\mathrm{DALY}=\mathrm{YLL}+\mathrm{YLD}
$$

where YLD (morbidity) is the number of new cases of disease, the severity of the disability (D from 0 to $1=$ death) and the average duration of the disability in Chronic (L):

$$
\mathrm{YLD}==\mathrm{I} \times \mathrm{DW} \times \mathrm{L}
$$

YLL (mortality) corresponds to the number of deaths $(\mathrm{N})$ and the Standard Life expectancy at the age in which death occurred (L):

$$
\mathrm{YLL}=\mathrm{N} \times \mathrm{L}
$$

In particular, $\mathrm{L}$ can be further regulated by discounting future life expectancy (from the future to present value) and taking into account the relative value of one year of life at different ages (age weighting).

1. Cardiovascular diseases: The evidence from epidemiological studies on the association between exposure to road traffic and aircraft noise, and hypertension and ischemic heart disease has increased during recent years. Road traffic noise has been shown to increase the risk of ischemic heart disease, including myocardial infarction. Both road traffic noise and aircraft noise increase the risk of high blood pressure. 
2. Sleep disturbance: Sleep disturbance can be measured electro-physiologically or by self-reporting in epidemiological studies using survey questionnaires. In epidemiological studies, "self-reported sleep disturbance" is the most easily measurable outcome indicator.

3. Tinnitus: Tinnitus is defined as the sensation of sound in the absence of an external sound source. Tinnitus caused by excessive noise exposure has long been described; $50 \%$ to $90 \%$ of patients with chronic noise trauma report tinnitus.

4. Annoyance: Health is a state of complete physical, mental, and social well-being and not merely the absence of disease. Therefore, a high level of annoyance caused by environmental noise should be considered as one of the environmental health burdens $[18,19]$.

\subsection{Acoustic Comfort and Sonic Identities Assessment Methodology}

This evaluation is realized during the completion of the strategic noise maps of the agglomeration. Based on the results from the SNM correlated with simultaneously real-time acoustic measurements, several subareas of the city are selected in order to understand in depth the perception of inhabitants of the whole sound environment [20]. The goal of this part of the study is to structure a noise action plan within a framework in order to preserve also the soundscapes of the places. As defined by R. Murray Schafer in his book "The tuning of the world" [21], soundscape is an environment of sound (or sonic environment) with emphasis on the way it is perceived and understood by the individual, or by a society. It thus depends on the relationship between the individual and any such environment. The term may refer to actual environments, or to abstract constructions such as musical compositions and tape montages, particularly when considered as an artificial environment [21]. Resident perception of the soundscape in this way is assessed through a set of questionnaires (semi-directive ones) in which airplane traffic is considered as one source of the environment that can be heard in situ. As described in [12], questionnaires do not focus only on the annoyance potentially created by environmental sources, but try to understand more deeply the impact of such noise in everyday life of the neighborhood studied. In another words, soundscape evaluation is not only considered by the noise properties of the acoustics signal of the airplanes but, more globally, by the assessment of this source by residents in the general evaluation of their living environment. In such context, perception of soundscape might differ in between people because of other factors that do not have any links with the acoustic signal (quality of life, of the habitations, quality of the public spaces, of public services, etc.). Soundscape is a perceptual construct [20] in which sound dimension is one of the several dimensions of the perceived phenomena [22].

It is for this reason that several analytical maps were produced and each of them analyzes different aspects related to the qualities of the sound environment: the specific type of street sections (U-shaped street, L-shaped, semi-open, open) to better understand the spatial context of sounds propagation, the specific type of sound effects produced by buildings and the master plan, a map of land and public space uses and a map of building uses in order to understand the spatial localization of the whole sound sources of the environment. The results constitute a total analysis of the "in situ" surveys with the inhabitants. This process makes it possible to reveal the sound indicators and the sound markers of the studied subareas [13] as described by Schafer (sound indicators indicate what kind of sources are heard by the residents and the sound markers are sounds that can be only heard in the neighborhood and do not exist somewhere else). Both indices and markers maps can be used to understand and describe the sound qualities of the environments and perceptual dimensions of the soundscapes of the places.

The results describe how sonic comfort by the residents of a neighborhood is perceived and assessed. They describe the place of noise in all sources of the environment and, above all, allow a certain number of recommendations to be made for the management of the soundscape in relation to the recommendations of the Noise Action and Soundscape Plan [15]. 


\section{Strategic Noise Maps-Main Results}

In this methodological frame, the International Airports of Heraklion and Corfu have been assessed and the results of the study can be used in order to explain how this interdisciplinary methodology can bring to light new solutions mitigating environmental noise pollution.

\subsection{SNM of International Airport of Heraklion-Main Results}

The main results from strategic noise map of the Heraklion agglomeration are presented in Table 1 and Figure 5. The exposure to the noise classes, to which the inhabitants of the agglomeration are exposed due to airport noise, exclusively, is evident.

Table 1. Strategic Noise Map of Heraklion-Population exposure in noise zones of airport noise.

\begin{tabular}{ccccc}
\hline \multirow{2}{*}{ Noise Zones dB(A) } & \multicolumn{4}{c}{ Population Exposure per Index (Residents \& \%) } \\
\cline { 2 - 5 } & $\mathbf{L}_{\text {den }}$ & $\mathbf{L}_{\text {night }}$ & $\mathbf{L}_{\mathbf{d e n}} \%$ & $\mathbf{L}_{\text {night }} \%$ \\
\hline$<45$ & 37.987 & 73.474 & $26.2 \%$ & $50.8 \%$ \\
$45-50$ & 27.700 & 23.392 & $19.1 \%$ & $16.2 \%$ \\
$50-55$ & 24.024 & 24.641 & $16.6 \%$ & $17.0 \%$ \\
$55-60$ & 24.950 & 14.130 & $17.2 \%$ & $9.8 \%$ \\
$60-65$ & 18.432 & 5.739 & $12.7 \%$ & $4.0 \%$ \\
$65-70$ & 6.170 & 3.398 & $4.3 \%$ & $2.3 \%$ \\
$70-75$ & 5.177 & 0 & $3.6 \%$ & $0.0 \%$ \\
$>75$ & 334 & 0 & $0.2 \%$ & $0.0 \%$ \\
Total & 144.774 & 144.774 & $100.0 \%$ & $100.0 \%$ \\
\hline
\end{tabular}

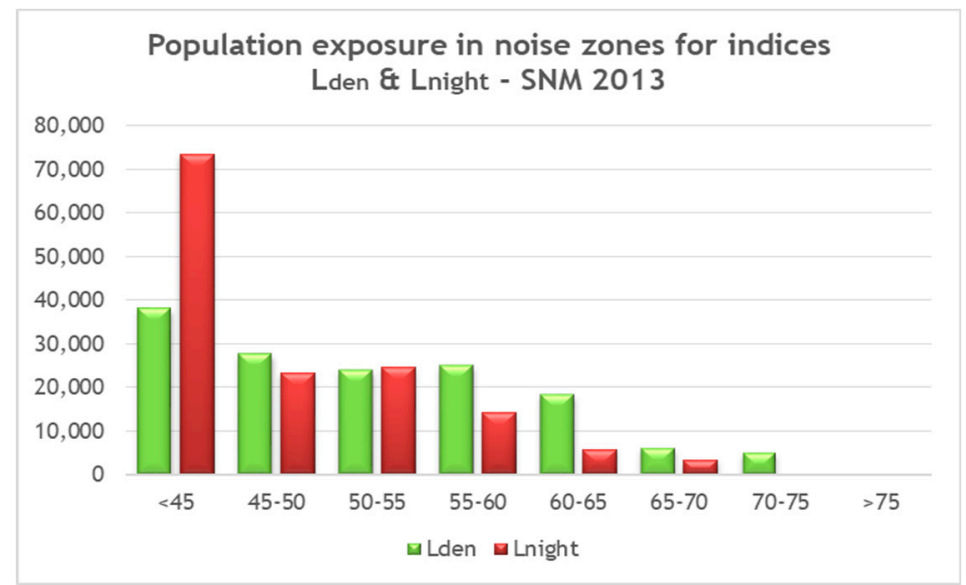

Figure 5. Heraklion Strategic Noise Map (SNM)—population exposure in noise zones for indices $\mathrm{L}_{\mathrm{den}}$ \& $\mathrm{L}_{\text {night. }}$

Regarding the results of SNM, it is obvious that the operation of the Airport affects the population and the area around the Airport. However, only $3.8 \%$ of the population is over $70 \mathrm{~dB}(\mathrm{~A})$ for the index $\mathrm{L}_{\mathrm{den}}$ and $6.3 \%$ of the population over $60 \mathrm{~dB}(\mathrm{~A})$ for the index $\mathrm{L}_{\text {night }}$.

\subsection{SNM of International Airport of Corfu-Main Results}

In the same way, Table 2 and Figure 6 present the exposure to the noise classes to which the inhabitants of the agglomeration are exposed due to airport noise exclusively. 
Table 2. Strategic Noise Map of Corfu-Population exposure in noise zones of airport noise.

\begin{tabular}{ccccc}
\hline \multirow{2}{*}{ Noise Zones dB(A) } & \multicolumn{4}{c}{ Population Exposure per Index (Residents \& \%) } \\
\cline { 2 - 5 } & $\mathbf{L}_{\text {den }}$ & $\mathbf{L}_{\text {night }}$ & $\mathbf{L}_{\text {den }} \%$ & $\mathbf{L}_{\text {night }} \%$ \\
\hline$<45$ & 285 & 14.852 & $0.9 \%$ & $48.7 \%$ \\
$45-50$ & 7.682 & 7.707 & $25.2 \%$ & $25.2 \%$ \\
$50-55$ & 11.461 & 6.096 & $37.5 \%$ & $20.0 \%$ \\
$55-60$ & 5.341 & 1.841 & $17.5 \%$ & $6.0 \%$ \\
$60-65$ & 5.018 & 28 & $16.4 \%$ & $0.1 \%$ \\
$65-70$ & 735 & 0 & $2.4 \%$ & $0.0 \%$ \\
$70-75$ & 2 & 0 & $0.0 \%$ & $0.0 \%$ \\
$>75$ & 0 & 0 & $0.0 \%$ & $0.0 \%$ \\
Total & 30.524 & 30.524 & $100.0 \%$ & $100.0 \%$ \\
\hline
\end{tabular}

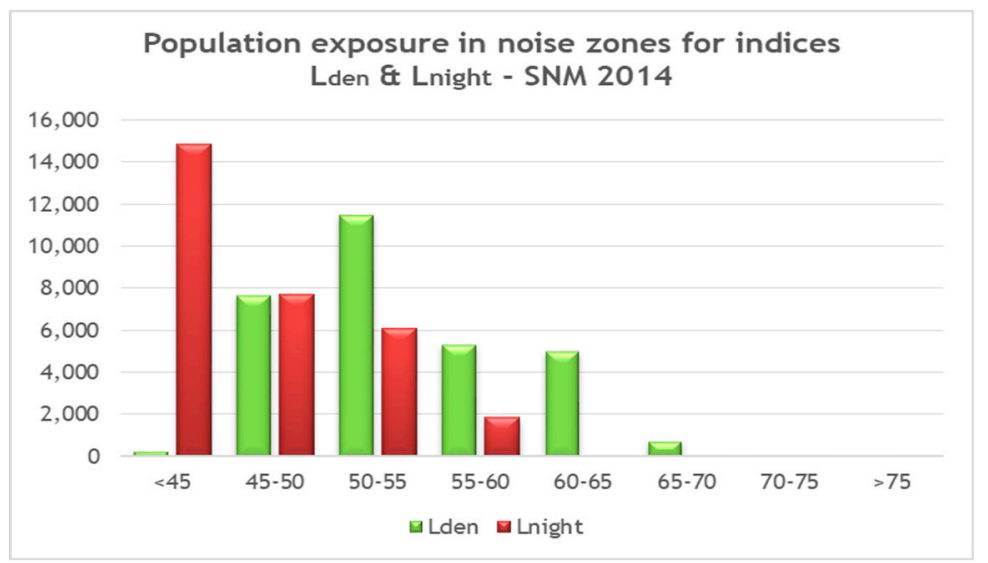

Figure 6. Corfu SNM-population exposure in noise zones for indices $\mathrm{L}_{\text {den }} \& \mathrm{~L}_{\text {night. }}$

In accordance with the results of $\mathrm{SNM}, 0.0 \%$ of the population is over $70 \mathrm{~dB}(\mathrm{~A})$ for the index $\mathrm{L}_{\mathrm{den}}$ and only $0.1 \%$ of the population over $60 \mathrm{~dB}(\mathrm{~A})$ for the index $\mathrm{L}_{\text {night }}$.

\section{Noise Health Assessment-Main Results}

With an appropriate calculation sheet, we define the health burden of disease due to long-term exposure to environmental noise from aircrafts and roads. To use it, we fill the number of people exposed per $5 \mathrm{~dB}(\mathrm{~A})$ bands to the different noise sources. Numbers do not necessarily need to refer to an entire country, they can be referred to a single airport, road or railway section, or agglomeration. All results are automatically generated [17]. The main results for the health burden of disease due to long-term exposure to noise from aircraft are described in Table 3.

Table 3. Main results for the health burden of disease due to long-term exposure noise from aircrafts.

(Disability Adjusted Life Year or DALY)

\begin{tabular}{ccc}
\hline Strategic Noise Map & Int. Airport Heraklion & Int. Airport Corfu \\
\hline Total Population & 144.774 & 30.524 \\
Cardiovascular (DALY per year) & 63 & 6 \\
Annoyance (DALY per year) & 372 & 89 \\
Sleep disturbance (DALY per year) & 388 & 75 \\
Tinnitus (DALY per year) & 3 & 1 \\
Cognitive impairment in children (DALY per year) & 509 & 126 \\
Total DALY & $1.336(0.92 \%)$ & $170(0.55 \%)$ \\
\hline
\end{tabular}

As shown in similar studies that use the same methodology for SNM and DALY's calculations [17], the total number of DALY for both cases oscillates between $0.50 \%$ and $0.90 \%$ of the global population of 
the city. In Heraklion, the value is higher due to the density of construction of the city (and population) and reaches 1336 DALYs. In comparison, Corfu is less exposed because of the density of the built spaces (and population) and also due to the fact that the noise produced by aircraft is less significant than in Heraklion. Strategic noise maps as presented in previous paragraphs show that the statistical percentage of population exposed to high levels of noise can be considered as significant in Heraklion, whereas not so much in Corfu.

Although 170 years lost due to air traffic in Corfu cannot be a satisfying number, it can be considered as a small value. It is interesting to note that this airport still has a small influence on the quality of life in this place. As far as the area of Heraklion is concerned, Alikarnassos district is located exactly at the border of the main corridor of the airport. It is also worth mentioning that the airport of Heraklion has airport traffic throughout the whole year, while Corfu airport operates more in the summer season, as it is a touristic destination.

\section{Sound Environment Analysis—Main Results}

Exposure-response functions can be used for strategic assessment. In translating environmental noise maps into overviews of numbers of persons annoyed, in cost-benefit analyses, and in environmental health impact assessments [19]. In our case, questionnaires with residents have been passed during the SNM and NAP time of survey. The interviews were recorded, transcribed on paper and analyzed according to the recurrence of the answers and descriptions proposed by the inhabitants. Main results are discussed in the following parts.

\subsection{Soundscapes of Alikarnassos-Airport of Heraklion}

The first qualitative result of the study on the sound environment is of course the noise mask created by the aircraft takeoffs from the international airport. The arrivals are events that are a little less noisy and shorter in duration. Wherever people are in the neighborhood, the mask is such that it forces them to pause their conversation and resume a few seconds later. Even though average values of $\mathrm{L}_{\mathrm{den}}$ and $\mathrm{L}_{\text {night }}$ are not so high, airplane traffic is an annoyance for almost $80 \%$ of the inhabitants. As shown on previous publications [12], 17-20\% also say that 'they get used to it' and this source of noise does not disturb them anymore (resigned) [11].

That is the reason why this paper proposes the continuation of the noise study by seeking to understand what the general perception of the sound environment of the specific neighborhood is. The ambition is to understand what the inhabitants who live in the particular area are experiencing in terms of the sound environment. This environmental study focuses on the sound qualities perceived by the inhabitants when they were not masked by the passage of planes. In other words, what is the noise comfort experience by the inhabitants when there are no plane passages?

From the analysis of all the interviews, 5 different sound identities emerge in the suburb of Alikarnassos, which are described in the following Figure 7:

- The "beach" (green Area in Figure 7) includes the coastal zone with the park and the fields along Agiou Dimitriou Street. The sound environment is characterized by the depth of road traffic and the sounds of the sea, harbor and human activities (audio indicators). It is a quiet place where people can enjoy both the visual and the sound landscape.

- The shopping area consisting of Icarus Avenue (red color), the industrial zone to the east and a third of Herodotou Street and sounds at the pace of commercial activities.

- The residential area is scattered throughout the subarea. It is a quiet zone (except for airplane crossings), with minimal sound indicators and generally audible events. Road traffic is mild. However, residents live mainly behind the road, in the open space of their-courtyard, while the space in front of the street is mainly used as a parking space for their car. It is a uniform band, both architecturally and acoustically (uniform levels of sound that are heard in the area). 


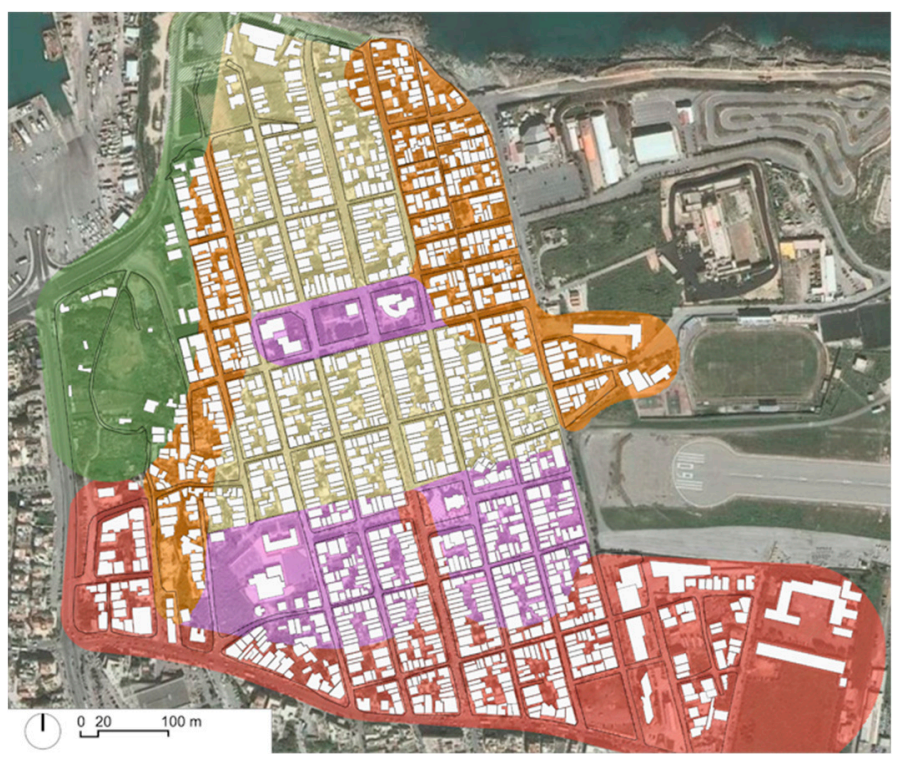

Figure 7. Heraklion-Five different sound identities in Alikarnassos district: the beach (green), the shopping area (red), the residential (yellow), urban squares (purple), small village (orange) [11].

Two sectors with different sound characteristics are observed inside the residential area. These are the areas around the two central meeting places of the residents. Because of their dynamic activities (cafes, parks, playgrounds, schools) and especially "open" public spaces, their sonic atmosphere diffuses to adjacent streets. They are vivid, like two urban squares that pleasantly disturb the quietness of the surrounding areas of residence, thus creating the feeling of an urban center where you can meet people, and enjoy a coffee or simply a chat on the sidewalk.

The western and northeastern zones of the subarea are characterized by a different "sound color". These are lively neighborhoods where the inhabitants themselves create their sonic identity. Audible indicators are mainly human sounds from conversations, children playing, voices heard from houses, radio and television and neighbors' music. Only the passage of planes disturbs this sound "world" of small villages.

\subsection{Soundscapes of Corfu一Airport of Corfu}

The subarea located in the south area of the peninsula is quite far away from the historical city centre. On the west side, the subarea overlooks the airport while, on its eastside, it overlooks the sea. The urban tissue is not dense and a lot of vegetation grows in between buildings. The site is mostly composed of tourism infrastructures such as hotels, coffee places, and apartments for summer time and rooms to rent (Figure 3). A few habitation house are welcoming the few permanent residents in the area that are also served by a few small stores. On all its east side, all the subarea is facing the airport and first habitations are located at less than $500 \mathrm{~m}$ from the runways.

Approximatively 119 interviews were conducted with tourists and with people who work and live in the subarea. Details of the answers were in the final report, published in English in [4], and are summarized below.

People interviewed appreciate the natural dimension of the site (trees, vegetation, and proximity of the sea) marking their representations of the place. Due to the proximity of the airport infrastructures and the proximity of the city center, a part of the population surveyed consider that this place is a part of Corfu city "center".

On the question about the influence of the road traffic in the place where they live or work, $80 \%$ of the population surveyed overwhelmingly indicated that they are not disturbed. The vast majority of the interviewees considered that the sound environment is quiet even though the quietness is 
sometimes interrupted by aircraft traffic. Interviewees also largely quote nature either in its generic sense ('nature') or by describing specific sounds like birdsongs and crickets.

Without a doubt, people come to this place to see and hear airplane departures and arrivals and it is fully logical that these sources are described as the main source of sound in this area. In comparison, sounds of human activities are objectively more present in the environment (people talking, car passes, music from coffee places, sound of coffee machines, ventilation, air conditioning) but sounds from airplanes are more often quoted. For residents and tourists who stay in the hotels there, it might be an annoyance but not during all day or all night. For example, it is a problem for workers whose conversations are masked by airplane land off because they cannot properly understand their customers' orders.

Despite all that, these sounds are also perceived as an attraction and a lot of people come to see and enjoy it. Most of the people do not complain about this noise when they sleep even though air traffic only stops between 4 and 5 a.m. during the night. Most of the people describe the tranquility of the Corfu city and actually do not consider the sound environment to be annoying.

\section{New Solutions Mitigating Environmental Noise Pollution}

The work on the two airports has made it possible to propose new solutions to solve the noise problems due to the passage of planes.

The two airports are very different in terms of the quantity and size of planes they host. It is obvious that the relocation of Heraklion airport is the best solution to avoid the noise pollution experienced by the whole agglomeration and also by the residents of these spaces.

In Corfu, the acoustic study shows that things are for the moment more manageable and the impact of the airport remains weak on the agglomeration. It has even become an attraction because the topography of the site allows thousands of tourists to observe the landing and takeoff of planes from the terrace of their hotel or from a series of coffee places and restaurants at the end of the peninsula where the corridor starts close to the seafront.

In the two cases, there is no doubt that the removal of the source of inconvenience is the best solution, but these two studies also made the assumption that these airports would not move and that they, like all airports in Europe, will increase their traffic. The new solutions must then propose actions that take into account the passage of planes but must also take into consideration all the hours of the day and all the days of the year during which the district is not disturbed by planes.

In this sense, these solutions are not necessarily acoustic. They can be linked to urban planning, to the practices of public spaces and to activities hosted by neighborhood buildings. They are not directly acoustic, but they can have significant acoustic consequences on the sound comfort experimented by residents.

\subsection{New Mitigation Solutions for Alikarnassos Airport}

The subarea of Alikarnassos is adjacent to Heraklion airport and is therefore subject to the continuous passage of aircrafts. The proposed action plan considers that the airport is relocated and transferred to the area of Kastelli. However, the same action plan remains valid even if this does not happen immediately but after some years. In general, its aim is to highlight the sound qualities of the subregion that are heard when no airplane passes. After all, even if the noise of the aircraft (leading to disturbance of sleep, health, nervous exhaustion, atmospheric pollution) is undoubtedly present at times, during the rest of the hours, when there are no airplanes, the sound environment of the area is very quiet and calm.

Generally speaking, the sound environment of the Alikarnassos subarea has particular qualities. The action plan proposes the following simple recommendations, summarized as follows:

- Maintain the commercial activities at the southern boundary and in the central arteries of the district (Herodotou and Karia) 
- Reinforce the commercial and cultural activities around the square of Ag. Nicholas and the City Hall Park at the crossroads of Artemisias and Dionysios streets

- Create pedestrian streets in some transverse axes (such as Zafeira Street), mainly around educational buildings and public services (City Hall, IKA, churches, etc.)

- Promote pedestrian walks on the seafront, in order to make it easier to explore the neighborhood and the beach

- Create cycling routes inside and peripherally to the subarea (for example, on the beach, along the airport, and towards the area around the Church of St. Nektarios in the northeast)

- Abandoned spaces should be planted and new relaxation areas be proposed, such as small parks or green areas, insertion of fountains, creation of new playgrounds, etc.

\subsection{New Mitigation Solutions for Corfu Airport}

The study area in Corfu is located on the peninsula south of the city of Corfu, surrounded by the sea, while in the west it is adjacent to the International Airport.

From the analysis of the current situation and the answers to the interviews, it seems that the noise from the airport activities does not particularly bother certain specific groups of people, such as tourists and receptionists. On the contrary, the sight and sounds of the takeoff or landing of the airplanes are a pole of attraction in the area. Of course, the location is particularly beautiful. Kanoni and Pontikonisi are particularly popular with foreign and local tourists.

It is a sparsely populated area, and a significant part of it is wooded and very green. All traffic of vehicles (cars, buses, tourists, and bicycles) takes place on a one-way street. Along this road there are many buildings, permanent and seasonal residences, sports facilities, a church and several tourist accommodation and recreation centers (cafes, bars). The following action plan is proposed for this area bearing in mind that the natural beauty in Kanoni and Pontikonissi has to be enhanced so that it is more attractive for both locals and tourists.

It is also proposed that a network of walks, bicycle paths, or sports activities that could link the historical center of the city with the Kanoni area and Pontikonisi be created. This network would ensure:

- A $2.6 \mathrm{~km}$ long "sporting" route that will take advantage of the different topographic features of the area

- A network of pedestrian and promenade (for permanent and seasonal residents) in natural surroundings

Previous analyses have shown us that even if the planes cause several noisy events, the location itself is quiet, with sound levels at night below $40-45 \mathrm{~dB}(\mathrm{~A})$. This is also contributed by the fact that there is very little traffic and industrial activity in the area. The main sources of noise are related to touristic activities and are mainly heard in and around them. Therefore, it would be preferable to maintain the residence as the main use in the area and to prevent the strengthening of tourist activities such as night clubs, bars, and taverns.

\section{Discussion and Conclusions}

Heraklion and Corfu airports are both international airports where the aircraft traffic tends to increase every consecutive year due to the continuous growth of tourism in Greece and especially these two destinations. The proximity of the airport facilities in both city centers is also a common parameter between the two sites. The noise emissions are quite comparable, taking into account, anyway, the size of each airport remaining in both cases the major source of noise pollution sites. However, both are differentiated to each other regarding their direct impact on the acoustic environment and the health of residents, with the main noise health impacts to be comparable to the aircraft movements volume with a total of 1336 DALY's for Heraklion and a total of 170 for Corfu respectively. The primary resolution is that, in the case of the Heraklion International Airport, relocation is the necessary and proper noise 
action plan; however in the case of Corfu's airport, the city center proximity is a major parameter of acoustic degradation that can be managed with the appropriate tools.

For both international airports, a more detailed study regarding the sound environment through resident and tourist interviews has been conducted in order to understand how this specific noise is impacting every day the life of the city inhabitants. Even if in both cases, the noise of the aircraft is regarded as an important annoyance source, as per the above relevant analysis the affected urban neighborhoods needs to be also considered as urban spaces offering a sound environment of quality for their inhabitants in case of no aircraft movements. There are, indeed, places that are also appreciated for the quality of the sound environment especially when the background sound is not masked by the aircraft environmental noise. DALY's metric also indicates the differences in between the two airports and can be a quantitative measurement of the quality of the global sound environment. Indeed, the expected health consequences in Corfu airport are mainly on the working and residential population inside the surrounding areas. That is why a comprehensive soundscape analysis within an appropriate noise action plan may ensure to the "user" resident the possibility to experiment and explore the space, e.g., by walking, jogging, cycling, etc., promoting the perception of the nature of the urban area both along the coastline and the interior of the peninsula. Accordingly, in the Alikarnassos area near Heraklion Airport, a very rich soundscape is present and the relevant analysis indicates that even in the worst case scenario of no airport relocation, conventional noise abatement mitigation measures introducing low noise procedures for aircraft (e.g., limitation of night traffic, etc.) accompanied by urban developments may reinforce the existing qualities of the soundscape as perceived by local residents. However, the measure of mitigation-already in motion through the construction and operation of the new Airport at Kasteli-will completely erase the effect of aircraft noise annoyance, introducing a radical rehabilitation of the acoustic environment [11].

This analysis presents how the combination of both the application of the European Directive $2002 / 49$, and the DALY's approach consist of a quality analysis tool for the appraisal of the sound environment ensuring the evaluation of all potential noise sources on all sites possible, offering the opportunity to understand their impact on the population and finally to evaluate the extent of considering their impact as an urban nuisance. This approach describes the acoustic behavior of urban neighborhoods in proximity to both airport infrastructures with different movement volumes in order to propose a holistic noise action plan founded in both quantity and quality analysis tools aimed at successful management of the sound environment through several new acoustic and nonacoustic mitigation solutions by minimizing the airport noise impact.

Author Contributions: K.V. was in charge of the application of the Directive for Strategic Noise Mapping for major cities, highways, and airports in Greece. In this frame, he collaborated with G.G. and V.Z., specialized in Noise Health assessment, noise measurement, and simulations and also with N.R., specialized in soundscape studies. Together they wrote the present paper.

Funding: this research received no external funding.

Conflicts of Interest: The authors declare no conflict of interest.

\section{References}

1. Stassen, K.R.; Collier, P.; Torfs, R. Environmental burden of disease due to transportation noise in Flanders (Belgium). Transp. Res. Part D Transp. Environ. 2008, 13, 355-358. [CrossRef]

2. Directive 2002/49/Ec of the European Parliament and of the Council of 25 June 2002 relating to the assessment and management of environmental noise. Off. J. Eur. Communities L 2002, 189, 2002.

3. EU Commission-Final Report-Annual Analysis related to the EU Air Transport Market 2016. 2017. Available online: https:/ / ec.europa.eu/transport/sites/transport/files /2016_eu_air_transport_industry_ analyses_report.pdf (accessed on 12 January 2018).

4. Gagliardi, P.; Teti, L.; Licitra, G. A statistical evaluation on flight operational characteristics affecting aircraft noise during take-off. Appl. Acoust. 2018, 134, 8-15. [CrossRef] 
5. Licitra, G.; Ascari, E.; Brambilla, G. Comparative analysis of methods to estimate urban noise exposure of inhabitants. Acta Acust. Acust. 2012, 98, 659-666. [CrossRef]

6. Postorino, M.N.; Mantecchini, L. A systematic approach to assess the effectiveness of airport noise mitigation strategies. J. Air Transp. Manag. 2016, 50, 71-82. [CrossRef]

7. Goldschagg, P.L. Using supplemental aircraft noise information to assist airport neighbours understand aircraft noise. Transp. Res. Part D 2013, 21, 14-18. [CrossRef]

8. Licitra, G.; Gagliardi, P.; Fredianelli, L.; Simonetti, D. Noise mitigation action plan of Pisa civil and military airport and its effects on people exposure. Appl. Acoust. 2014, 84, 25-36. [CrossRef]

9. Evrard, A.S.; Bouaoun, L.; Champelovier, P.; Lambert, J.; Laumon, B. Does exposure to aircraft noise increase the mortality from cardiovascular disease in the population living in the vicinity of airports? Results of an ecological study in France. Noise Health 2015, 17, 328. [CrossRef] [PubMed]

10. Cassina, L.; Fredianelli, L.; Menichini, I.; Chiari, C.; Licitra, G. Audio-visual preferences and tranquility ratings in urban areas. Environments 2018, 5, 1. [CrossRef]

11. Vogiatzis, K.; Remy, N. Strategic Noise Mapping of Herakleion: The aircraft noise impact as a factor of the Int. Airport relocation. Noise Mapp. J. 2014, 1, 15-31. [CrossRef]

12. Vogiatzis, K.; Remy, N. Assessment of the Environmental Noise due to Aircraft Operation at the CORFU International Airport according to the 2002/49/EC Directive and the new Greek national Legislation. In Proceedings of the Euronoise 2015, Maastricht, The Netherlands, 31 May-3 June 2015.

13. Vogiatzis, K.; Remy, N. Soundscape design guidelines through noise mapping methodologies: An application to medium urban agglomerations. Noise Mapp. J. 2017, 4, 1-19. [CrossRef]

14. Vogiatzis, V.; Remy, N. From environmental noise abatement to soundscape creation through strategic noise mapping in medium urban agglomerations in South Europe. Sci. Total Environ. J. 2014, 482-483, 420-431. [CrossRef] [PubMed]

15. Vogiatzis, K.; Remy, N. Changing the Urban Sound Environment in Greece: A Guide Based on Selected Case Studies of Strategic Noise Maps (SNM) and Noise Action Plans (NAP) in Medium and Large Urban Areas. Environments 2018, 5, 64. [CrossRef]

16. European Civil Aviation Conference. ECAC.CEAC. Doc 29, Report on Standard Method of Computing Noise Contours around Civil Airports, 2-3 July 1977. Available online: https: / / www.ecac-ceac.org/ecac-documents?p_p_id=101\&p_p_lifecycle=0\&p_p_state=maximized\&p_ p_mode=view\&_101_struts_action=\%2Fasset_publisher\%2Fview_content\&_101_assetEntryId $=245876 \&$ _101_type=content\&_101_urlTitle=ecac-directors-general-endorse-the-new-edition-of-ecac-doc-29-onstandard-method-of-computing-noise-contours-around-civil-airports (accessed on 12 December 2018).

17. World Health Organization European Centre for Environment and Health; Bonn Office; WHO Regional Office for Europe. Burden of Disease from Environmental Noise, Quantification of Healthy Life Years Lost in Europe, 2011. Available online: http:/ / www.euro.who.int/_data/assets / pdf_file/0008/136466/e94888.pdf (accessed on 12 December 2018).

18. Ganic, E.; Dobrota, M.; Babic, O. Estimation of airport noise impacts on public health. A case study of Izmir Adnan Menderes Airport. Transp. Res. Part D Transp. Environ. 2016, 36, 152-159.

19. Miedema, H.M.; Oudshoorn, C.G. Annoyance from Transportation Noise: Relationships with Exposure Metrics DNL and DENL and Their Confidence Intervals. Environ. Health Perspect. 2001, 109, 409. [CrossRef] [PubMed]

20. ISO 12913-1:2014: Acoustics—Soundscape-Part 1: Definition and Conceptual Framework. Available online: https:/ / www.iso.org/standard/52161.html (accessed on 01/12/2018).

21. Schafer, R.M. The Tuning of the World; Knopf: New York, NY, USA, 1977.

22. Augoyard, J.F. L'objet sonore ou l'environnement suspendu. In Oü̈r, entendre, écouter, comprendre après Schaeffer; Ina-Buchet Chastel: Paris, France, 1999; pp. 83-106. Available online: http:/ / doc.cresson.grenoble. archi.fr $/$ index.php?lvl=notice_display\&id=2572 (accessed on 01/12/2018).

(C) 2019 by the authors. Licensee MDPI, Basel, Switzerland. This article is an open access article distributed under the terms and conditions of the Creative Commons Attribution (CC BY) license (http:/ / creativecommons.org/licenses/by/4.0/). 